\title{
Chronic suppurative lung disease in sisters mimicking cystic fibrosis
}

\author{
J. J. COGSWELL, R. A. RISDON, and BRENT TAYLOR \\ From The Hospital for Sick Children, Great Ormond Street, London
}

\begin{abstract}
Cogswell, J. J., Risdon, R. A., and Taylor, B. (1974). Archives of Disease in Childhood, 49, 520. Chronic suppurative lung disease in sisters mimicking cystic fibrosis. Two sisters are described with fatal chronic obstructive lung disease of unknown origin. The lung condition was clinically and histologically indistinguishable from cystic fibrosis and the salivary glands showed pathological changes expected in cystic fibrosis. Neither child had abnormal sweat electrolytes, they had no bowel symptoms, and the pancreas was normal at necropsy.
\end{abstract}

The most common cause of chronic suppurative lung disease in childhood is cystic fibrosis (CF). Though few physicians would accept a diagnosis of CF without a positive sweat test, Di Sant'Agnese and Vidaurreta (1960) stated that two of the following criteria are sufficient for the diagnosis. (1) Chronic respiratory involvement. (2) Pancreatic achylia. (3) Increased sweat electrolyte concentration. (4) Family history of the disorder.

In CF there may be pulmonary disease without overt gastrointestinal disease; indeed, Shwachman (1972) states there may be pulmonary disease without any digestive or pancreatic involvement.

This paper describes 2 sisters with a fatal chronic respiratory disease, indistinguishable from $C F$. They are reported because neither had abnormal sweat electrolytes and both had normal pancreatic histology. Other possible causes of generalized chronic suppurative lung disease in childhood are discussed.

\section{Case reports}

Two Caucasian sisters, aged 9 and 6 years, were admitted to this hospital in January 1972. The parents were healthy and unrelated. The father had had a tuberculous effusion effectively treated in 1955, but intensive inquiry revealed no other family history of respiratory disease. 4 other sibs were healthy.

Case 1. The elder sister had a normal birth and neonatal period. She was breast fed for 9 months and received routine immunizations and BCG vaccine. She was well until age 4 years 9 months when she had an attack of measles. From that time she had recurrent

Received 12 November 1973. bronchitis with cough and purulent sputum. The condition was progressive with frequent hospital admissions. She became breathless on exercise at the age of 6 years, and for 6 months before her final admission she was orthopnoeic. She had no gastrointestinal symptoms.

Examination showed an extremely ill, wasted, prepubertal girl. She was breathless at rest, centrally cyanosed, and had gross finger clubbing. She had a productive cough with purulent sputum. The chest was hyperinflated and there were coarse rales and expiratory rhonchi in all areas.

Case 2. The younger sister also had a normal birth and neonatal period. She was also breast fed and received BCG vaccination. She was noticed to have a cough soon after birth, and by 3 months of age she had been in hospital 3 times with respiratory infections. These respiratory symptoms began 18 months before the older sister became symptomatic. The clinical picture was similar to that of her sib, with decreasing exercise tolerance and a productive cough. She had no gastrointestinal symptoms. Neither child had ever shown evidence of recurrent infections outside the respiratory tract. Treatment of both children with antibiotics and postural drainage was carried out in hospital during acute exacerbations.

Her clinical condition was similar to that of her sister. She was centrally cyanosed with clubbing of fingers and toes. Her cough was productive of mucopurulent sputum. The chest was hyperinflated with coarse crepitations in all areas.

Investigations. Both children were considered to have advanced obstructive airway disease of uncertain aetiology. Fig. 1 shows a chest $x$-ray from Case 1 on her final admission. The chest $x$-ray appearance in Case 2 was very similar. 


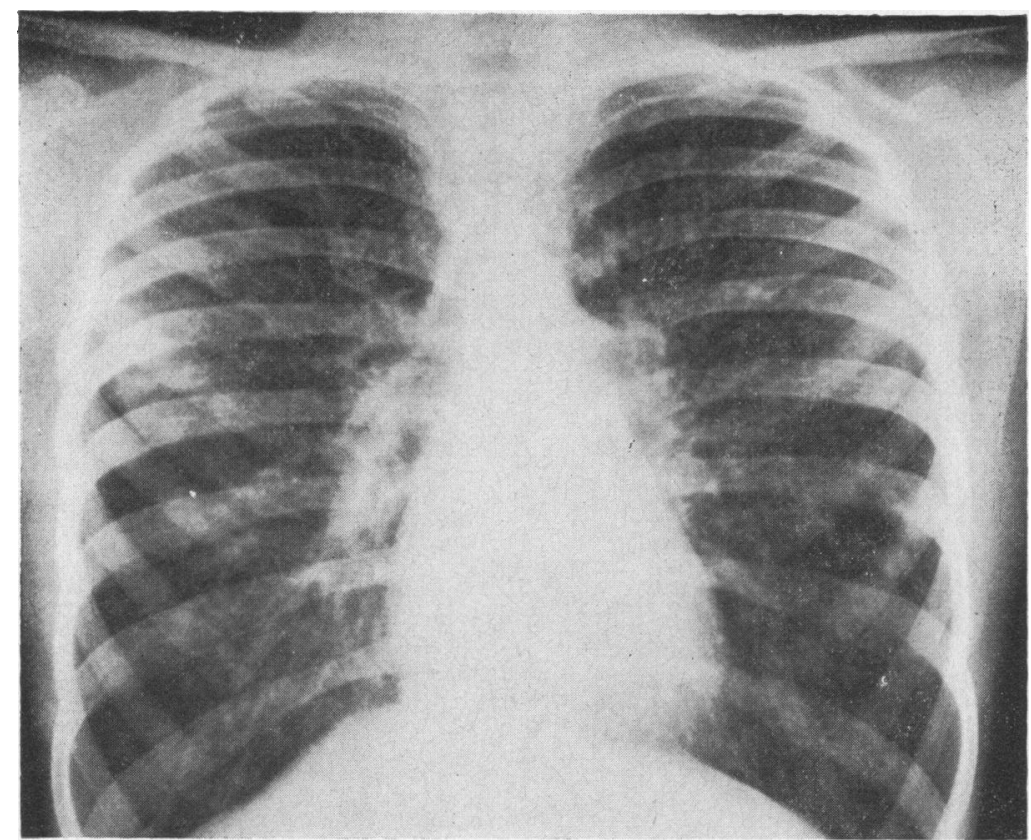

FIG. 1.-Case 1. Chest $\mathrm{x}$-ray of older sib showing fine mottling, hyperinflation, bronchial wall thickening, and ring shadows.

Respiratory function tests (Table I) confirmed the severe hyperinflation and airway obstruction. The older child was too ill to tolerate plethysmography, but the high thoracic gas volume with apparently normal functional residual capacity values in the younger sib suggested gross hyperinflation with air trapping.

The laboratory investigations are shown in Table II. Serum from both children and their father inhibited the cilia motility of the fresh water mussel. Mother's serum did not.

Both sisters had received BCG in infancy but both were Mantoux negative. Prick skin tests to a wide variety of antigens were all negative.
Serum IgG and IgA were high. IgA and IgM in secretions were high in Case 2. Other tests of immune function were normal (Table III). Sweat tests on both sisters on several occasions, in both this hospital and during earlier hospital admissions, gave normal sodium concentrations (Table II).

Clinical course. Both children were treated with I.V. antibiotics and intensive postural drainage of the lungs. Case 1 deteriorated rapidly and died within 5 days of admission, aged 9 years. Case 2 improved only slightly during 2 months in hospital despite continuing

TABLE I

Respiratory function tests

\begin{tabular}{|c|c|c|c|c|}
\hline & \multicolumn{2}{|c|}{ Case 1} & \multicolumn{2}{|c|}{ Case 2} \\
\hline & Recorded & Predicted & Recorded & Predicted \\
\hline $\begin{array}{l}\text { Age }(\mathrm{yr}) \\
\text { Height }(\mathrm{cm}) \\
\text { Weight }(\mathrm{kg}) \\
\text { Peak flow rate }(1 . / \mathrm{min}) \\
\text { Vital capacity (ml) } \\
\text { Forced expiratory volume }(1 \mathrm{sec}) \\
\quad \text { (ml) } \\
\text { Forced expiratory volume } \\
\quad(0 \cdot 75 \mathrm{sec})(\mathrm{ml}) \\
\text { Functional residual capacity }(\mathrm{ml}) \\
\text { Thoracic gas volume }(\mathrm{ml}) \\
\text { Airway resistance } \\
\quad\left(\mathrm{cm} \mathrm{H}_{2} \mathrm{O} / 1 . \text { per sec) }\right.\end{array}$ & $\begin{array}{r}9 \cdot 5 \\
128 \\
22 \\
60 \\
500 \\
280 \\
225 \\
1150 \\
- \\
-\end{array}$ & $\begin{array}{r}240 \\
1850 \\
1700 \\
1400 \\
1150 \\
- \\
-\end{array}$ & $\begin{array}{l}6 \cdot 2 \\
111 \\
15 \cdot 5 \\
45 \\
380 \\
200 \\
150 \\
725 \\
2070 \\
15 \cdot 5\end{array}$ & $\begin{array}{r}170 \\
1200 \\
1100 \\
900 \\
750 \\
800 \\
6\end{array}$ \\
\hline
\end{tabular}


TABLE II

General investigations

\begin{tabular}{|c|c|c|}
\hline & Case 1 & Case 2 \\
\hline $\begin{array}{l}\text { Haemoglobin }(\mathrm{g} / 100 \mathrm{ml}) \\
\text { White blood count/mm } \\
\text { Neutrophils }(\%) \\
\text { Lymphocytes }(\%) \\
\text { Monocytes }(\%) \\
\text { Chest } x \text {-ray } \\
X \text {-ray sinuses } \\
X \text {-ray } \\
\text { Post nasal } \\
\text { Abdominal } \\
\text { Barium meal } \\
\text { ECG } \\
\text { Sputum culture } \\
\text { Urine } \\
\text { Stool tryptic activity (BAEE units) } \\
\text { Sweat test (sodium mEq/1.) } \\
\text { (right and left arms) }\end{array}$ & $\begin{array}{l}17,200 \\
65 \\
25 \\
10 \\
\text { Gross emphysema; bronchial wall } \\
\text { thickening; widespread mottling } \\
\text { Opaque R antrum } \\
\text { Normal calibre } \\
\text { Normal } \\
\text { Sinus tachycardia; right ventricular } \\
\text { hypertrophy } \\
\text { Staphylococcus aureus, Pseudomonas } \\
\text { Normal } \\
\text { 47 and } 31 \\
\\
\text { No growth } \\
\text { Negative } \\
<1 \text { in } 8 \\
\text { Negative } \\
\text { Negative }\end{array}$ & 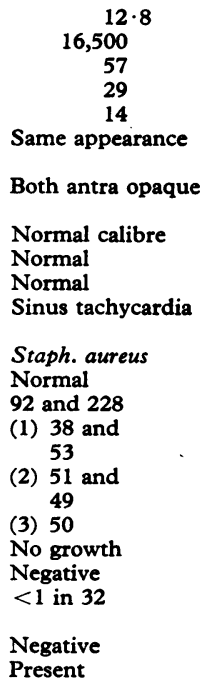 \\
\hline
\end{tabular}

TABLE III

Immunological function tests

\begin{tabular}{l|c|cc}
\hline & Case 1 & \multicolumn{2}{|c}{ Case 2 } \\
\cline { 2 - 3 } Immunoglobulins (IU/ml) & Serum & Serum & Tears \\
IgG & 200 & 168 & - \\
IgA & 280 & 180 & 23 \\
IgM & 96 & 268 & 13 \\
Schick test & - & Negative \\
ASO titre (IU/ml) & 64 & 64 \\
$\begin{array}{l}\text { Skin test for Candida } \\
\text { albicans }\end{array}$ & Negative & - \\
Isohaemaglutinins & $1: 512$ & $1: 1024$ \\
$\quad \begin{array}{l}\text { Anti A } \\
\text { Anti B }\end{array}$ & $1: 128$ & $1: 512$ \\
BIC complement (\% of & & 132 \\
standard) & 100 & Normal \\
Lymphocyte function & Normal & None \\
Response to PHA & Nesponse to PPD & & \\
\end{tabular}

intensive therapy; she died at age 6 years, 3 months after her sister.

Necropsy findings. The findings in both children were essentially similar.

The trachea and main bronchi in both were congested and filled with yellow mucopus. The lungs were grossly emphysematous with small areas of pulmonary collapse. On sectioning the lungs, the distal bronchi showed tubular dilatation (Fig. 2) and many contained mucopus.

The pancreas in both cases showed a normal lobular pattern and consistency. The livers were not enlarged and were macroscopically normal.
Histological examination of the lungs showed distension of the bronchioles with mucopurulent secretion and peribronchiolar extension of the inflammation. There was also peribronchiolar pulmonary collapse (Fig. 3). The main bronchi contained mucopurulent material. The mucous glands were distended with mucus and focally the glandular ducts were blocked with mucous secretion (Fig. 4).

Sections of the sublingual glands in Case 1 showed enlargement of the mucous acini with ballooning of the cells and slight distension of the ducts by mucous secretion (Fig. 5).

The pancreas in both cases showed no changes of fibrocystic disease. In Case 1 there was extensive autolysis, but in neither case was there any excess fibrosis nor distension of acini or small ducts. Islets of Langerhans were present in normal numbers.

The livers were histologically normal apart from some nonspecific fatty changes. The cervix uteri in Case 1 showed no abnormalities in the cervical glands.

\section{Discussion}

Identical disease in 2 of 6 sibs with normal parents is consistent with an inherited autosomal recessive condition. In both sisters the respiratory disease was clinically, bacteriologically, functionally, and radiologically characteristic of CF. The necropsy findings in the trachea, lungs, and sublingual salivary glands were typical of those found in CF (Andersen, 1938, 1962; Bodian, 1952). 


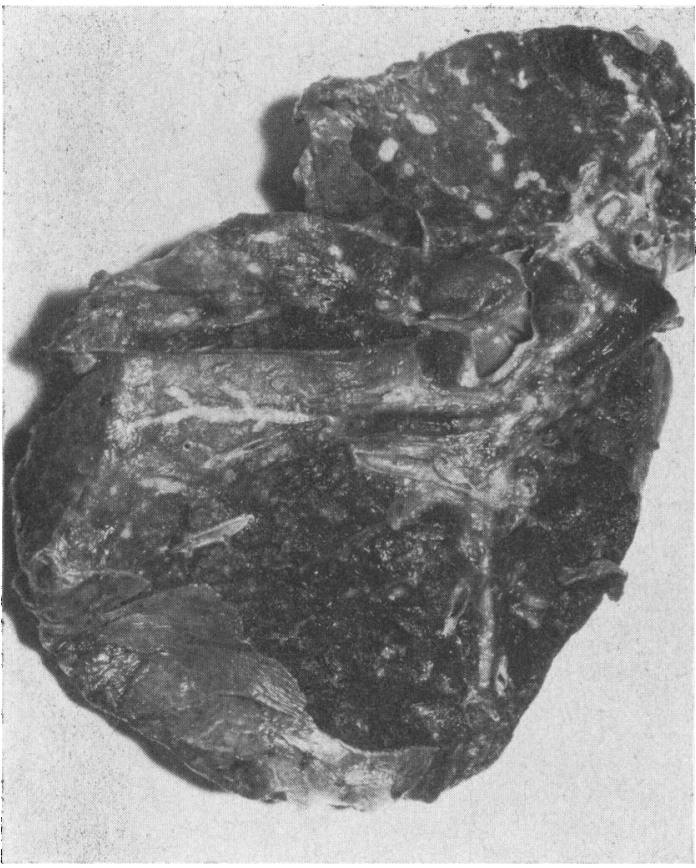

FIG. 2.-Case 1. The sliced lung showing generalized purulent bronchiectasis and pulmonary collapse.

On the other hand, neither child had gastrointestinal symptoms and necropsy showed none of the changes of CF in the pancreas. In addition, repeated sweat tests were normal on adequate collections of sweat $(>100 \mathrm{mg}$ ) (Table II). The sweat electrolyte abnormality in $\mathrm{CF}$ is present throughout life and there is usually wide separation of sweat sodium values between patients with $\mathrm{CF}$ and virtually all other normal or diseased subjects (Shwachman, 1962). However, Di Sant'Agnese et al. (1953) reported $1 \%$ of cases with CF to have sweat electrolytes within the normal range.

The finding of the serum factor (Spock et al., 1967) is of little diagnostic significance. This factor which inhibits ciliary activity in the fresh water mussel (Besley, Patrick, and Norman, 1969) is found in heterozygotes as well as homozygotes. Its absence from the mother's serum makes it most unlikely that the children's condition was CF, though false negative inhibition tests do occur and there is some evidence that CF patients and their parents may be genetically heterogeneous (Bearn and Danes, 1969).

No definite diagnosis could be established. No unusual infecting organism was found. The different onset and progressive clinical course at

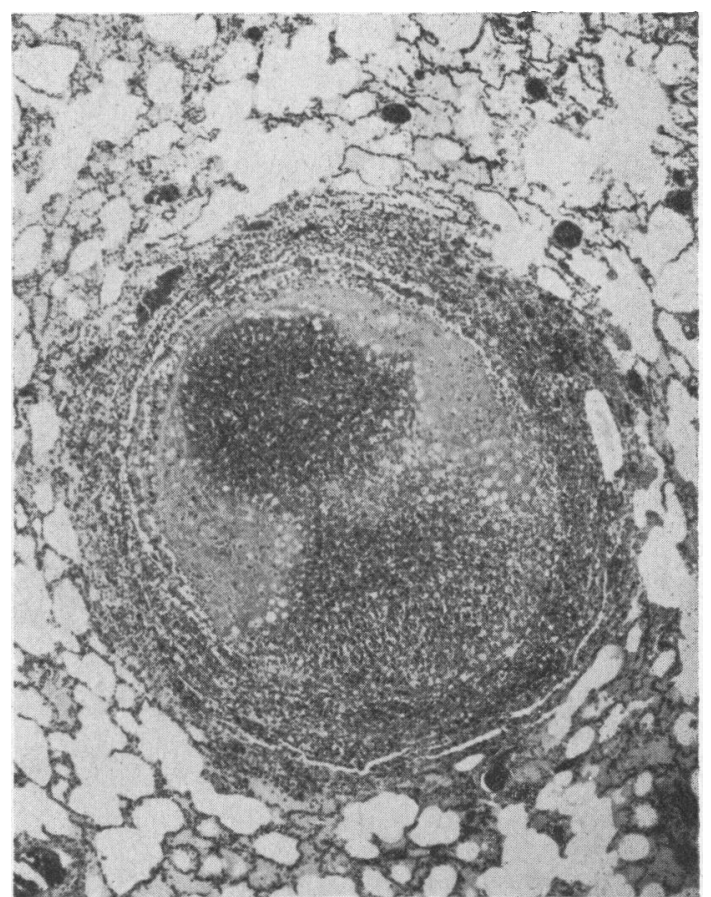

FIG. 3.-Case 1. A bronchiole markedly distended with m.ucopurulent secretion. There is peribronchiolar extension of the inflammation and some peribronchiolar collapse. (H. and $E$. $\times 7$.)

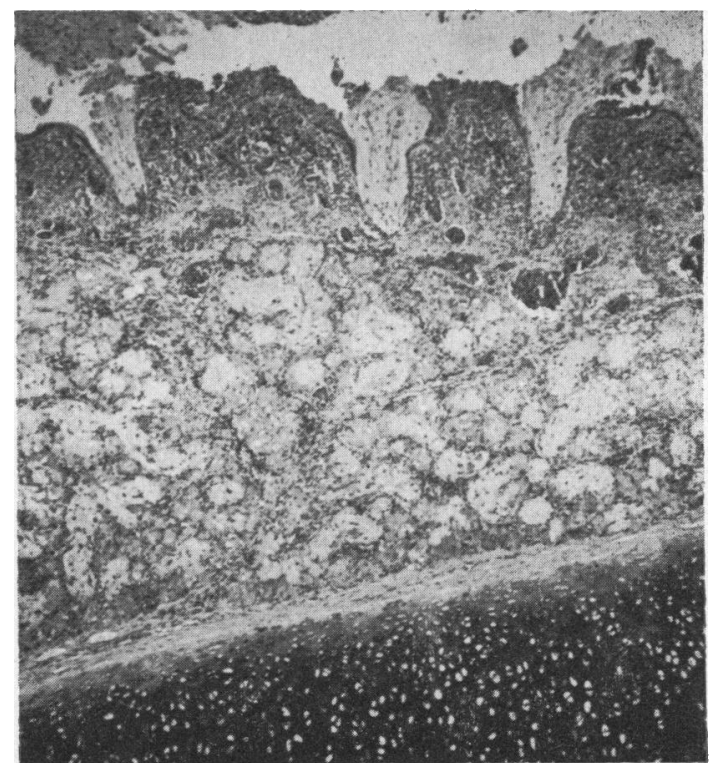

FIG. 4.-Case 2. Bronchial wall showing distension of the mucous glands and plugging of glandular ducts with secretion. (H. and $E . \times 6$.) 


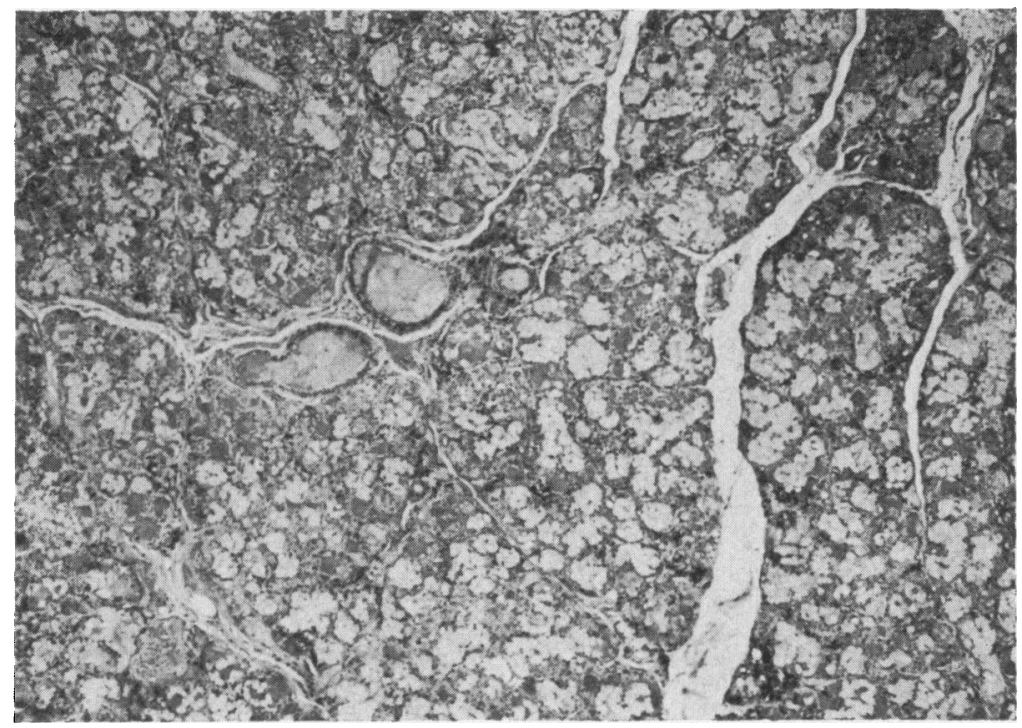

FIG. 5.-Case 1. Sublingual gland showing focal ballooning of the glandular epithelial cells and distension of the ducts by secretion. (H. and E. $\times 7$.)

different times in the 2 children largely excludes an infectious cause for their obliterative bronchiolitis such as that described by Becroft (1971) after adenovirus type 21 infection. The disease in the older child became manifest after an attack of measles. Measles is often a very serious disease in $\mathrm{CF}$ and may precipitate a downwards course (Shwachman, 1972).

No immunological deficit could be defined. The negative tuberculin tests, in spite of infantile BCG inoculation, probably reflect anergy in the face of severe illness. Bronchomalacia (Williams, Landau, and Phelan, 1972), a generalized bronchiectasis due to extensive deficiency of bronchial cartilage, was excluded at necropsy. Necrotizing bronchiolitis, with secondary bronchiectasis, after measles might be postulated in the case of the older sister, but would not explain the condition in the younger; nor was the histology suggestive of this or other types of bronchiectasis, and changes in the salivary glands are not described in such conditions.

It is clearly impossible to accept these cases as typical of cystic fibrosis. Nevertheless, with 2 cases in one family it is tempting to suggest a pure pulmonary form of the disease.

We thank Professor David Hull for permission to publish these cases and Dr. A. P. Norman for his advice. We also thank Dr. M. d'A Crawfurd, Department of Medical Genetics, Leeds University, for carrying out the investigations on cilia motility. B.T. is in receipt of a Cystic Fibrosis Research Trust Fellowship.
Andersen, D. H. (1938). Cystic fibrosis of the pancreas and its relation to celiac disease. American fournal of Diseases of Children, 56, 344.

Andersen, D. H. (1962). Pathology of cystic fibrosis. In Problems in Cystic Fibrosis. Annals of the New York Academy of Sciences, 93, 500 .

Bearn, A. G., and Danes, B. S. (1969). A genetic study of cystic fibrosis of the pancreas in cell culture. Transactions of the Association of American Physicians, 82, 248.

Becroft, D. M. O. (1971). Bronchiolitis obliterans, bronchiectasis, and other sequelae of adenovirus type 21 infection in young children. Fournal of Clinical Pathology, 24, 72.

Besley, G. T. N., Patrick, A. D., and Norman, A. P. (1969). Inhibition of the motility of gill cilia of Dreissensia by plasma of cystic fibrosis patients and their parents. Fournal of Medical Genetics, 6, 278.

Bodian, M. (1952). Fibrocystic Disease of the Pancreas: A Congenital Disorder of Mucus Production-Mucosis. Heinemann, London.

Di Sant'Agnese, P. A., Darling, R. C., Perera, G. A., and Shea, E. (1953). Abnormal electrolyte composition of sweat in cystic fibrosis of the pancreas. Clinical significance and relationship to the disease. Pediatrics, 12, 549.

Di Sant'Agnese, P. A., and Vidaurreta, A. M. (1960). Cystic fibrosis of the pancreas. Fournal of the American Medical Association, 172, 2065.

Shwachman, H. (1962). The sweat test. Pediatrics, 30, 167.

Shwachman, H. (1972). Cystic fibrosis. In Pulmonary Disorders. Vol. 1 of Disorders of the Respiratory Tract in Children, 2nd ed., p. 524. Ed. by E. L. Kendig, Jr. Saunders, London.

Spock, A., Heick, H. M. C., Cress, H., and Logan, W. S. (1967). Abnormal serum factor in patients with cystic fibrosis of the pancreas. Pediatric Research, 1, 173.

Williams, H. E., Landau, L. I., and Phelan, P. D. (1972) Generalized bronchiectasis due to extensive deficiency of bronchial cartilage. Archives of Disease in Childhood, 47, 423.

Correspondence to Dr. B. Taylor, Respiratory Unit, The Hospital for Sick Children, Great Ormond Street, London WC1N 3JH. 